\title{
Lampu Cerdas Multimode Menggunakan Arduino dengan Kontrol Fuzzy Berbasis Android
}

\author{
Siti Febriyanti Riski Rullah dan Nanta Fakih Prebianto* \\ Teknik Elektro, Politeknik Negeri Batam, Batam, Indonesia \\ *Email: nanta@polibatam.ac.id
}

\begin{abstract}
Abstrak-Umumnya pengaturan sebuah intensitas cahaya pada lampu di dalam suatu ruangan dilakukan hanya berdasarkan pada kondisi gelap dan terang yang dilakukan secara manual dan tanpa mempertimbangkan kontribusi cahaya dari luar. Oleh karena itu, diperlukan sebuah alat yang bekerja secara otomatis pada pengontrolan intensitas cahaya lampu untuk meningkatkan efisiensi pemakaian energi listrik. Prinsip kendali yang digunakan pada penelitian ini adalah kendali logika fuzzy dengan sistem inferensi metode Mamdani. Keluarannya diperoleh berdasarkan titik berat dari kurva hasil proses pengambilan keputusan sebagai hasil nilai dari output logika fuzzy. Modul WiFi NodeMCU digunakan sebagai media penghubung kendali yang dikoneksikan ke Android melalui aplikasi Blynk. Dengan pengujian menggunakan metode fuzzy singleton, diperoleh membership function dan membership keluarannya. Agar sesuai dengan intensitas ruangan, maka Set point yg diberikan ialah 40 pada mode tidur, 180 pada mode makan, dan 250 pada mode kerja. Pada mode tidur, diperoleh waktu delay 1,5 detik dan nilai Pulse Width Modulation (PWM) 18 pada kondisi stabil. Pada mode makan, diperoleh waktu delay 3 detik dan nilai PWM 83 pada kondisi stabil. Pada mode kerja, diperoleh waktu delay 3,6 detik dan nilai PWM 116 pada kondisi stabil.
\end{abstract}

Kata Kunci: Android, fuzzy Mamdani, NodeMCU, Blynk

\section{Pendahuluan}

SAAT ini, salah satu kendala yang sering dihadapi manusia dalam keseharian melakukan aktivitas adalah penerangan yang terkadang dapat membuat kurang nyaman. Pada umumnya, pengaturan penerangan hanya menggunakan prinsip on/off saja, yaitu dikendalikan dengan saklar untuk mematikan dan menyalakan lampu. Hal ini menyebabkan mata kita tidak nyaman saat melakukan aktivitas karena intensitas cahaya yang tidak memenuhi standar. Mata menjadi kurang sehat jika dihadapkan dengan cahaya yang begitu terang maupun terlalu gelap.

Untuk mengatasi permasalahan ini, penulis memanfaatkan logika fuzzy untuk merepresentasikan nilai dari intensitas cahaya yang ada, kemudian disesuaikan kedalam mode lampu yang di inginkan. Nilai yang didapat oleh pengukuran intensitas cahaya pada light intensity sensor akan dieksekusi oleh logika fuzzy untuk mengatur kecerahan lampu karena sifat dari logika fuzzy yang humanis untuk merepresentasikan sebuah nilai menjadi jelas [1].

Dengan memanfaatkan fuzzy, penelitian ini membuat sebuah lampu cerdas yang dapat dengan mudah dikontrol melalui Android dan menjadikan nilai intensitas cahayanya sesuai pada kebutuhan kita saat beraktivitas.

\section{TINJAUAN PUSTAKA}

\section{A. Intensitas cahaya}

Intensitas cahaya adalah kuat cahaya yang dikeluarkan sebuah sumber cahaya ke arah tertentu dan diukur menggunakan luxmeter dengan satuan internasional Candela (Cd). Pada umumnya cahaya memiliki empat faktor yang dapat mempengaruhi kualitas pencahayaan yaitu kontras, silau, refleksi cahaya dan kualitas warna cahaya. Kemampuan mata manusia hanya dapat melihat cahaya dengan panjang gelombang tertentu yang diukur dalam besaran pokok ini.

Intensitas cahaya monokromatik $\left(I_{v}\right)$ pada panjang gelombang $\lambda$ dapat dihitung menggunakan (1), di mana $I$ adalah intensitas radian dan $\bar{y}(\lambda)$ adalah fungsi intensitas standar. Tabel I menunjukkan standar intensitas cahaya pada sebuah ruangan di rumah yang telah dilakukan uji coba oleh [2].

$$
I_{v}=683 \sqrt{y}(\lambda)
$$

\section{B. Fuzzy Logic}

Penelitian ini menggunakan logika fuzzy [3], [4] untuk mengatur intensitas cahaya lampu sesuai dengan kondisi kecerahan ruangan. Input yang dijadikan sebagai variabel adalah hasil pembacaan sensor cahaya (light intensity sensor) dalam ruangan. Sistem berbasis aturan fuzzy logic control dengan variabel linguistik, yaitu suatu interval numerik dan mempunyai nilai-nilai linguistik, yang semantiknya 
didefinisikan oleh fungsi keanggotaannya. Sistem berbasis aturan fuzzy terdiri atas tiga komponen utama: fuzzification, inference, dan defuzzification.

TABEL I

NILAI INTENSITAS CAHAYA PADA RUANGAN

\begin{tabular}{|c|c|}
\hline Fungsi ruangan & Tingkat Pencahayaan (Lux) \\
\hline Teras & 60 \\
\hline Ruang tamu & $120-150$ \\
\hline Ruang makan & $120-250$ \\
\hline Ruang kerja & $120-250$ \\
\hline Ruang tidur & $120-250$ \\
\hline Ruang mandi & 250 \\
\hline Dapur & 250 \\
\hline Garasi & 60 \\
\hline
\end{tabular}

Proses fuzzifikasi pada sistem ini dimulai dari mendapatkan data berupa nilai lux dan Set point yang telah ditentukan. Kemudian nilai error akan didapat dari jarak antara set point dan nilai lux. Selanjutnya nilai error dapat diturunkan untuk mendapatkan $\Delta$ error. Pada langkah berikutnya, nilai error dan delta error akan menjadi input fuzzy. Kedua nilai ini akan diubah ke nilai crisp dengan membership function. Setelah mendapatkan nilai sesuai membership function maka dilakukan proses inference yaitu proses implikasi dengan operator MIN dan MAX. Pada Penelitian ini menggunakan operator MAX, setiap nilai crisp yang didapatkan akan dicari nilai maksimum sesuai zona nya guna menentukan nilai output pada proses defuzzifikasi. Output yang dihasilkan adalah nilai Pulse Width Modulation (PWM) yang nantinya akan di jumlahkan dengan PWM sebelumnya untuk mengatur kecerahan lampu. Proses terus berlanjut hingga nilai sensor menuju titik stabil.

Fuzzy inference system yang merupakan sebuah kerangka kerja perhitungan berdasarkan konsep teori himpunan fuzzy dan pemikiran fuzzy yang digunakan dalam penarikan kesimpulan atau suatu keputusan. Penarikan kesimpulan ini diperoleh dari sekumpulan kaidah fuzzy. Di dalam fuzzy inference system minimal harus terdapat dua buah kaidah fuzzy. Fuzzy inference system terbagi menjadi dua metode, yaitu metode Sugeno dan metode fuzzy Mamdani. Perbedaan dari kedua metode ini terletak pada output yang dihasilkan, proses komposisi aturan, dan defuzzifikasinya. Pada metode Sugeno, output yang dihasilkan berupa fungsi linear atau konstanta. Output ini berbeda dengan yang dihasilkan oleh metode fuzzy Mamdani, di mana metode ini menghasilkan output berupa suatu nilai pada domain himpunan fuzzy yang dikategorikan ke dalam komponen linguistik.

Kelemahan dari output berupa fungsi linear atau konstanta adalah nilai output yang dihasilkan harus sesuai dengan nilai yang telah ditentukan. Hal ini menimbulkan masalah apabila nilai output tidak sesuai dengan kriteria yang telah ditentukan. Output ini dapat dikatakan benar apabila dapat menyajikan output yang ditentukan oleh antesenden. Oleh karena itu, Metode fuzzy Mamdani lebih akurat dalam menghasilkan suatu output berupa himpunan fuzzy.

\section{METODE}

\section{A. Perangkat Keras}

Rancangan perangkat keras dapat dilihat pada Gambar 1. Sistem terdiri atas power supply, Arduino Nano, modul Wi-Fi NodeMCU, lampu DC 12V/5W, dan sensor cahaya BH1750 [5]. Skematik rangkaian dapat dilihat pada Gambar 2.
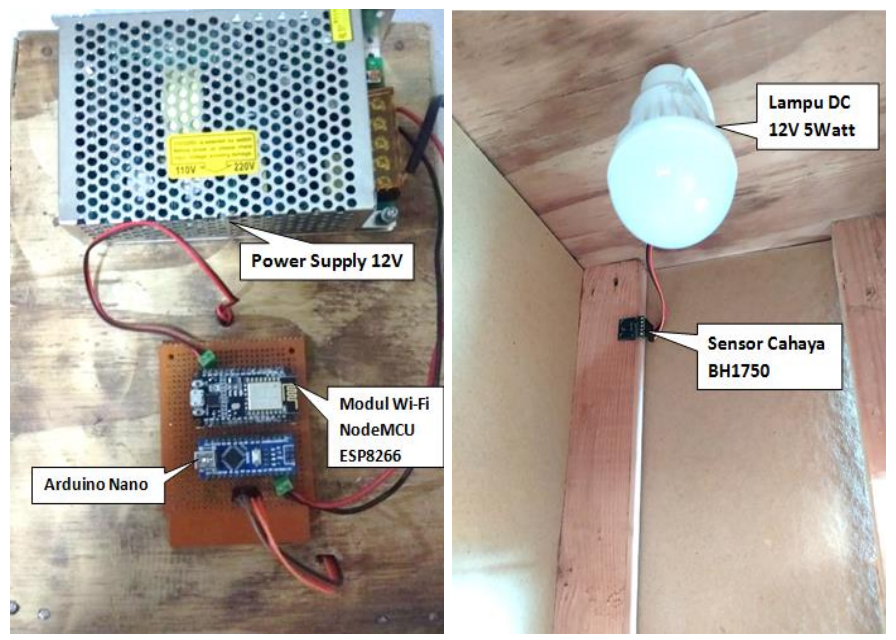

Gambar 1. Rancangan perangkat keras

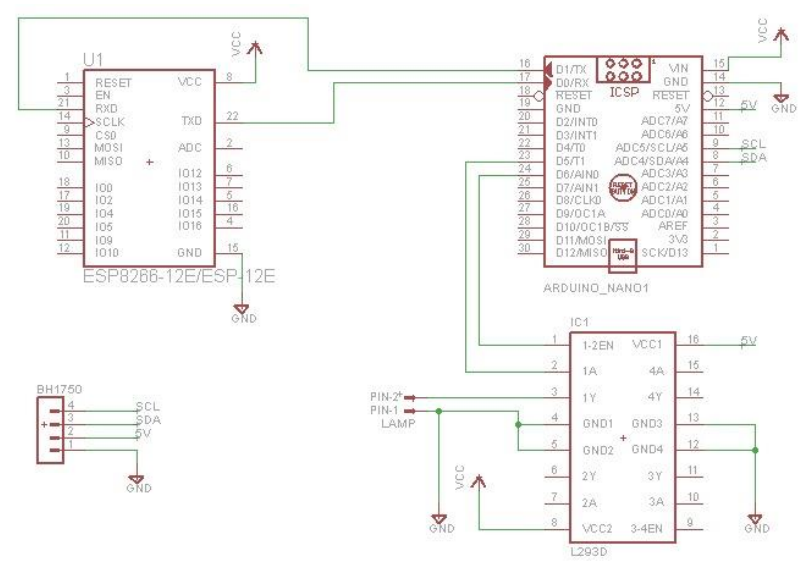

Gambar 2. Skematik rangkaian

\section{B. Perancangan Mekanikal}

Rancangan mekanikal dari sistem yang dibuat dapat dilihat pada Gambar 3 dan Gambar 4. Gambar 4 dilakukan pada saat pengujian dalam keadaan lampu menyala.

\section{Perancangan Perangkat Lunak}

Pada penelitian ini, aplikasi dibuat pada operating system Android guna menampilkan menu kendali yang akan memberikan perintah kepada perangkat lainnya. Android dihubungkan dengan modul Wi-Fi NodeMCU sebagai klien, lalu Android akan meminta password yang disediakan oleh NodeMCU. Jika NodeMCU sudah terhubung ke Wi-Fi, maka proses eksekusi oleh Arduino akan dijalankan sesuai data masukan dari sensor cahaya (light intensity sensor) yang telah mendeteksi intensitas cahaya pada lampu. Logika fuzzy akan mengambil perannya guna merepresentasikan nilai dari 
intensitas cahaya tersebut menjadi sesuatu yang pasti. Gambar 5 menjelaskan flowchart pada program Arduino yang telah terhubung ke modul Wi-Fi NodeMCU.
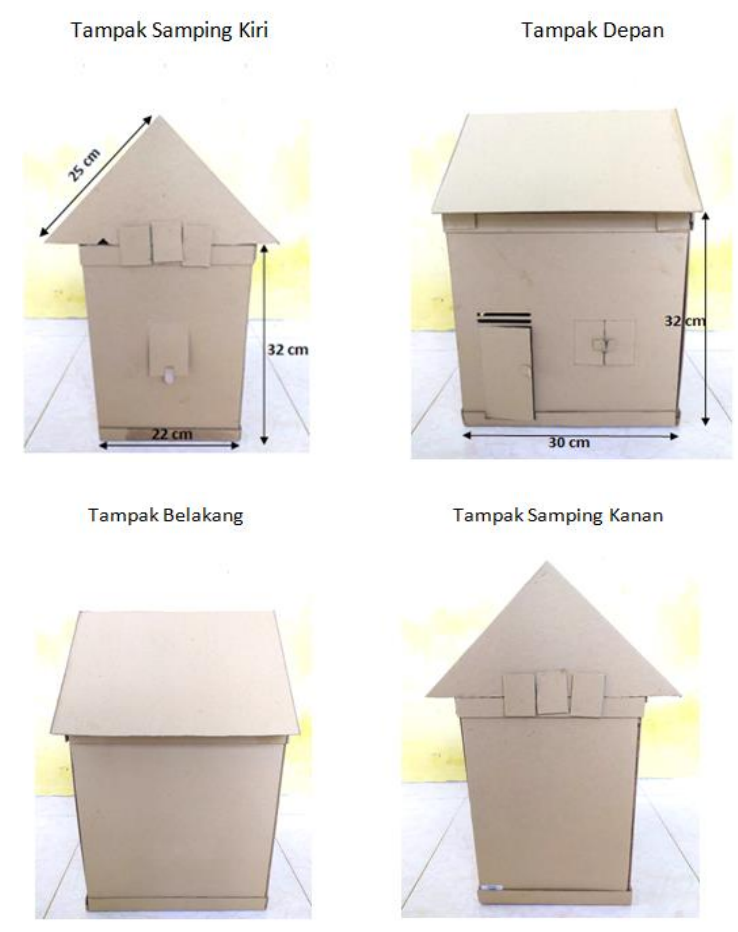

Gambar 3. Dimensi dan penampakan dari box simulasi

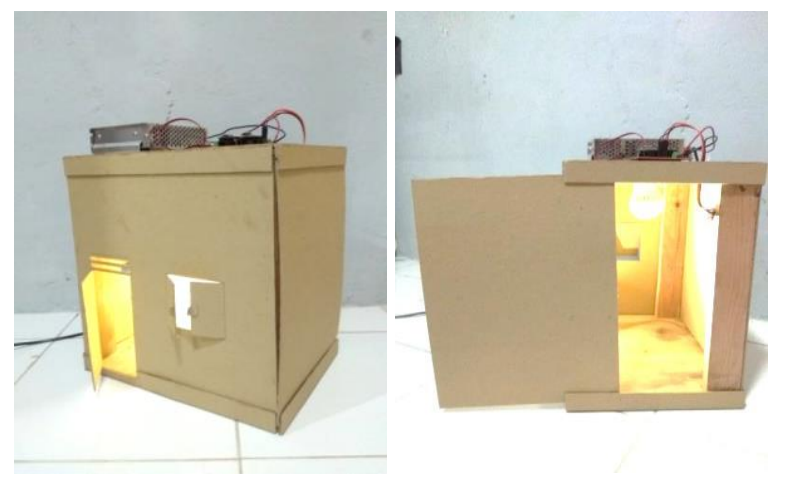

Gambar 4. Rancangan mekanikal pada saat pengujian lampu menyala

NodeMCU berperan sebagai client Wi-Fi. Saat sistem dihidupkan, NodeMcu akan terhubung ke access point yang telah diprogram. Setelah itu, ESP8266 akan masuk ke penyimpanan cloud Blynk sesuai kode autentikasi. Selanjutnya, device membaca nilai-nilai dari cloud dan mengirimkannya ke Arduino melalui komunikasi serial. Arduino sebagai main akan stanby menunggu perintah dan mengirim data ketika off.

Saat pertama kali dihidupkan, posisi lampu diset dalam kondisi mati. Jika koneksi Wi-Fi sudah terhubung, Arduino akan membaca status pada cloud. Jika status lampu hidup, maka Arduino akan menghidupkan lampu dilanjutkan dengan membaca status mode. Pada penelitian ini terdapat 3 mode, yaitu mode tidur, makan, dan kerja, yang masing masing mode merepresentasikan Set point untuk kecerahan lampu. Ketika lampu hidup, Arduino akan langsung membaca sensor dan mendapatkan data pertama, selanjutnya data kecerahan akan dibandingkan dengan Set point yang ditentukan sebagai error.

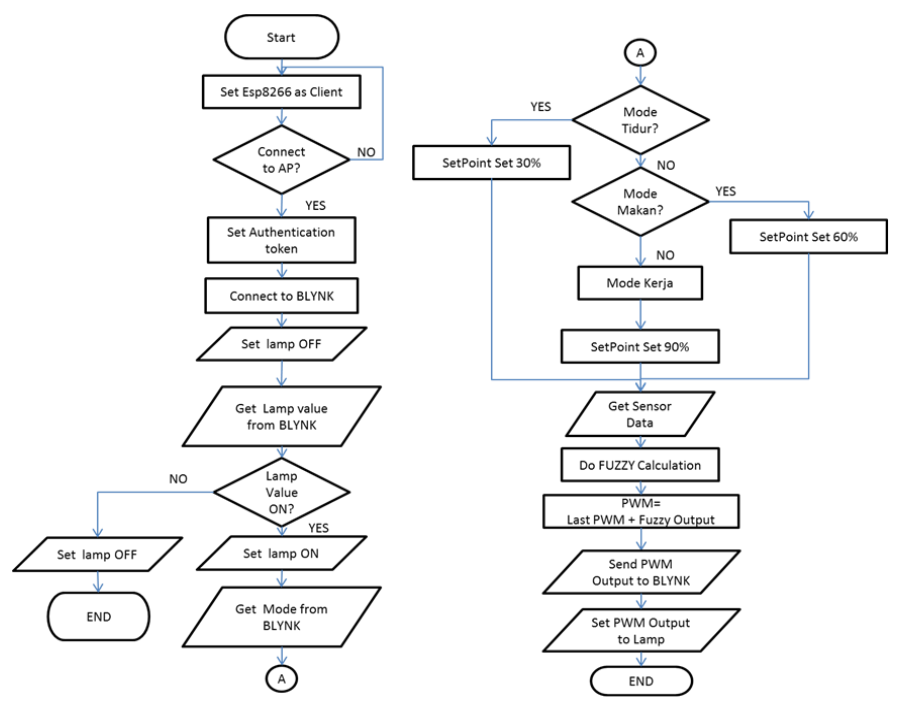

Gambar 5. Flowchart perancangan perangkat lunak

Setelah mendapatkan error, Arduino akan langsung melakukan perhitungan fuzzy (fuzzifikasi, inference, defuzzifikasi). Selanjutnya output akan di konversi ke PWM dan ditambahkan dengan nilai PWM sebelumnya. Proses ini akan berlangsung hingga nilai yang dibaca sensor akan mendekati atau sama dengan nilai Set point.

\section{Perancangan Aplikasi Android BLYNK}

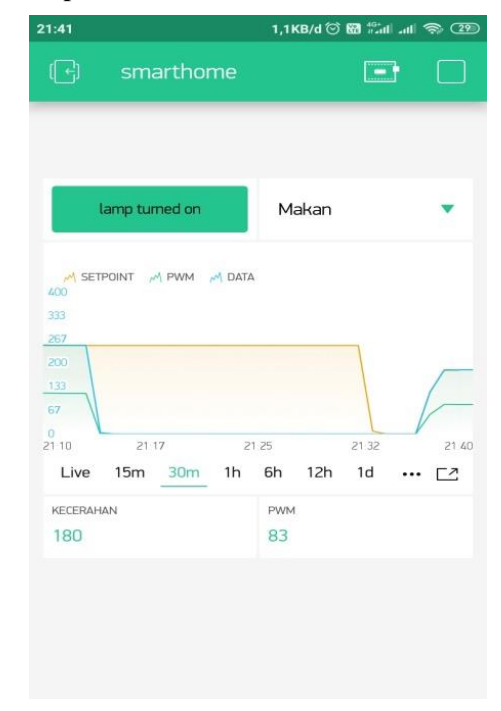

Gambar 6. Aplikasi Android BLYNK

Blynk (Gambar 6) adalah platform untuk IOS atau Android yang digunakan untuk mengendalikan modul Arduino, Rasbery Pi, ESP8266, Wemos D1, dan modul sejenisnya melalui internet. Pada saat aplikasi dijalankan, akan muncul permintaan untuk mengaktifkan tethering hotspot pada program. Setelah aktif, modul Wi-Fi akan terhubung dengan hotspot dan mendapatkan IP Address. Kemudian, user meng-input IP Address yang tersedia. Jika IP Address valid, 
maka perangkat Android akan terhubung dengan alat kendali. Langkah selanjutnya adalah memilih mode kendali yang diinginkan.

\section{E. Perancangan Logika fuzzy}

Metode fuzzy yang digunakan pada penelitian ini adalah metode Mamdani atau dikenal dengan nama metode MaxMin. Pada penerapan pengontrolan intensitas cahaya ini, masukan fuzzy yang digunakan ialah error dan delta error. Set point ditentukan terlebih dahulu. Error merupakan selisih antara Set point dan output. Delta error merupakan selisih antara error sekarang dan error sebelumnya.

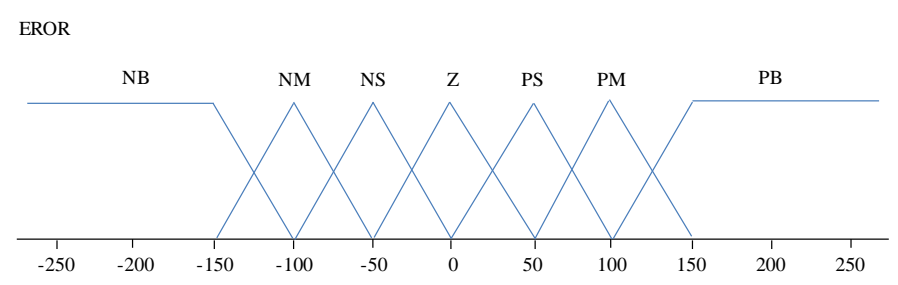

Gambar 7. Membership dari function error

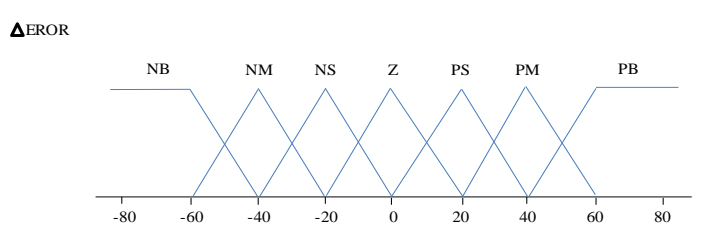

Gambar 8. Membership function dari delta error

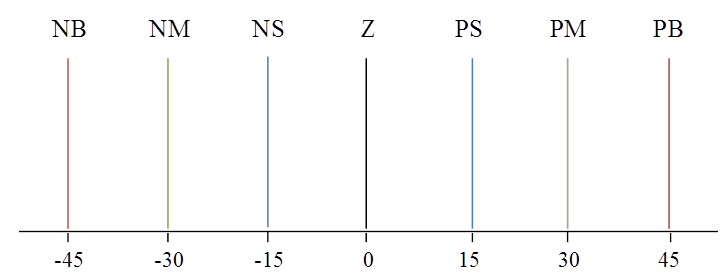

Gambar 9. Membership dari function keluaran

Error dan delta error memiliki 7 membership function yaitu Negative Big (NB), Negative Medium (NM), Negative Small (NS), Zero (Z), Positive Small (PS), Positive Medium (PM), dan Positive Big (PB). Keluarannya juga memiliki 7 membership function yang sama. Perhatikan Gambar 7, 8, dan 9.

Metode fuzzy mamdani dapat menghasilkan PWM negatif. Walaupun demikian, sebenarnya PWM tidak akan minus karena setiap perhitungan fuzzy akan menghasilkan PWM baru. Jika terdapat negatif maka akan di tambahkan lagi dengan PWM lama sehingga menjadi positif.

Setelah melakukan tahap fuzzifikasi, hasil dari fuzzifikasi akan diatur menggunakan basis aturan yang sudah dibuat. Aturan pada Tabel 1 dibuat untuk menghasilkan output yang sesuai dengan keinginan dari pembuat berdasarkan hitungan pada program. Proses bekerja nya fuzzy sehingga mendapatkan output keluaran adalah sebagai berikut: Set point $\rightarrow$ data diterima sensor $\rightarrow$ proses fuzzifikasi (melakukan proses perulangan akan terdapat error sebelum menuju set point $) \rightarrow$ mendapat hasil stabil $\rightarrow$ output sensor lux terbaca $\rightarrow$ output PWM terbaca.

TABEL II

FUZZY RULE

\begin{tabular}{|c|c|c|c|c|c|c|c|}
\hline & PB & PM & PS & Z & NS & NM & NB \\
\hline PB & PB & PB & PB & PM & PS & PS & Z \\
\hline PM & PB & PB & PM & PS & PS & Z & NS \\
\hline PS & PB & PM & PS & PS & Z & NS & NM \\
\hline Z & PM & PS & PS & Z & NS & NS & NM \\
\hline NS & PM & PS & Z & NS & NS & NM & NB \\
\hline NM & PS & Z & NS & NS & NM & NB & NB \\
\hline NB & Z & NS & NM & NM & NB & NB & NB \\
\hline
\end{tabular}

Dalam basis aturan membership function, titik tertinggi adalah pada mode kerja (yaitu 250) yang termasuk ke dalam rentan positive big. Mode makan juga masih termasuk ke dalam positive big dengan range 180. Mode tidur masuk kedalam positive small karena set point yang di masukkan 40.

\section{HASIL DAN PEMBAHASAN}

Berikut adalah data yang didapat atas pengujian yang dilakukan terhadap intensitas cahaya di dalam sebuah box serta terhadap perubahan nilai menggunakan fuzzy. Ada 3 mode yang digunakan yaitu mode tidur, makan dan kerja. Masing masing dari mode telah penulis tentukan set point-nya sebagai acuan, berdasarkan referensi serta pengamatan yang penulis lakukan sendiri agar mendapat cahaya yang pas di setiap mode nya. Penulis menentukan set point pada:

- Mode tidur dengan rentan range 0 - 40 lux

Pada sisi pengujian ini penulis menggunakan titik tertinggi yaitu 40 lux karena kondisi tersebut cukup redup untuk digunakan dalam pengujian ini.

- $\quad$ Mode makan dengan rentan range 0 - 180 lux

Pada sisi pengujian ini penulis menggunakan titik tertinggi yaitu 180 lux karena pada kondisi ini pencahayaan yang digunakan untuk makan tidak perlu begitu terang ataupun redup.

- Mode kerja dengan rentan range 0 - 250 lux. Pada sisi pengujian ini penulis menggunakan titik tertinggi yaitu 250 lux karena menurut penulis dalam kondisi ini kita membutuhkan pencahayaan yang terang agar pekerjaan menjadi maksimal.

Perlu di ketahui bahwa penyesuaian set point hanya dalam miniatur rumah pengujian yang digunakan karena kebutuhan pencahayaan akan berbeda tergantung dimensi pada ruangan tertentu.

\section{A. Pengujian Pada Mode Tidur}

Pengujian pada mode ini bertujuan mendapatkan kecerahan pada saat tidur di dalam sebuah ruangan. Set point yang diambil ialah 40. Hasil pengujian dapat dilihat pada Tabel III dan Gambar 10. Pada Gambar 10, pengambilan data dilakukan setiap $300 \mathrm{~ms}$. Set point yang ditentukan adalah 40 lux. Pada Gambar 10 terlihat bahwa data sensor bergerak dari 0 lux (kondisi lampu mati) ke 40 lux dalam waktu (data ke $\mathrm{n}_{\text {titik stabil }}$ - 
data ke $\left.\mathrm{n}_{\text {titik awal }}\right) \times 300 \mathrm{~ms}=(6-1) \times 300 \mathrm{~ms}=1,5$ detik. Titik stabil didapatkan karena antara sensor dan set point sudah tidak memiliki jarak (atau disebut zero error).

TABEL III

DATA PADA MODE TIDUR

\begin{tabular}{|c|c|c|c|}
\hline mode & setpoint (Ix) & Iux (Ix) & pwm \\
\hline \multirow{7}{*}{} & 0 & 0 & 0 \\
\cline { 2 - 4 } & 40 & 34,17 & 13 \\
\cline { 2 - 4 } & 40 & 28,33 & 16 \\
\cline { 2 - 4 } & 40 & 33,33 & 18 \\
\cline { 2 - 4 } & 40 & 38,33 & 18 \\
\cline { 2 - 4 } & 40 & 40 & 18 \\
\cline { 2 - 4 } & 40 & 40 & 18 \\
\cline { 2 - 4 } & 40 & 40 & 18 \\
\cline { 2 - 4 } & 40 & 40 & 18 \\
\cline { 2 - 4 } & 40 & 40 & 18 \\
\cline { 2 - 4 } & 40 & 40 & 18 \\
\cline { 2 - 4 } & 40 & 40 & 18 \\
\cline { 2 - 4 } & 40 & 40 & 18 \\
\hline
\end{tabular}

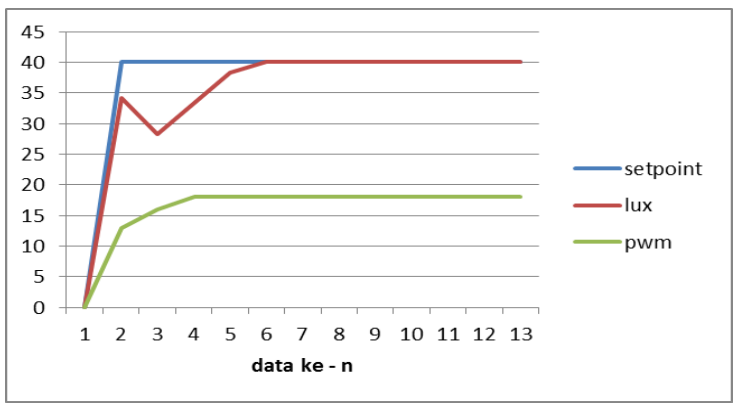

Gambar 10. Grafik pada mode tidur

\section{B. Pengujian Pada Mode Makan}

Pengujian pada mode ini bertujuan mendapatkan kecerahan pada saat makan di dalam sebuah ruangan. Set point yang diambil ialah 180. Berdasarkan hasil pengujian, didapatkan data seperti yang ditunjukkan pada Tabel IV dan Gambar 11. Pada kondisi mode makan ini dapat kita lihat garis sensor lux yang terbaca pada data ke-2 sedikit melewati garis set point. Hal ini terjadi karena pada perhitungan fuzzy data masih memiliki $\Delta$ (delta) error yang cukup tinggi sehingga masih menghasilkan jarak antara set point dan aktual.

TABEL IV

DATA PADA MODE MAKAN

\begin{tabular}{|c|c|c|c|}
\hline mode & setpoint (Ix) & Iux (Ix) & pwm \\
\hline \multirow{7}{*}{ makan } & 0 & 0 & 0 \\
\cline { 2 - 4 } & 180 & 215,83 & 104 \\
\cline { 2 - 4 } & 180 & 235 & 89 \\
\cline { 2 - 4 } & 180 & 207,5 & 81 \\
\cline { 2 - 4 } & 180 & 181,67 & 81 \\
\cline { 2 - 4 } & 180 & 175 & 82 \\
\cline { 2 - 4 } & 180 & 176,67 & 83 \\
\cline { 2 - 4 } & 180 & 177,5 & 83 \\
\cline { 2 - 4 } & 180 & 178,33 & 83 \\
\cline { 2 - 4 } & 180 & 179,17 & 83 \\
\cline { 2 - 4 } & 180 & 180 & 83 \\
\cline { 2 - 4 } & 180 & 180 & 83 \\
\cline { 2 - 4 } & 180 & 180 & 83 \\
\hline
\end{tabular}

Data terlihat menurun mendekati set point pada data ke-4, tetapi hal ini pun terlihat belum stabil hingga data ke-6. Sensor masih terlihat menjauhi ke bawah. Data mulai terlihat stabil pada data ke-11. Waktu yang dibutuhkan untuk lampu mencapai kecerahan stabil adalah (data ke $\mathrm{n}_{\text {titik stabil }}$ - data ke $\left.\mathrm{n}_{\text {titik awal }}\right) \times 300 \mathrm{~ms}=(11-1) \times 300 \mathrm{~ms}=3$ detik.

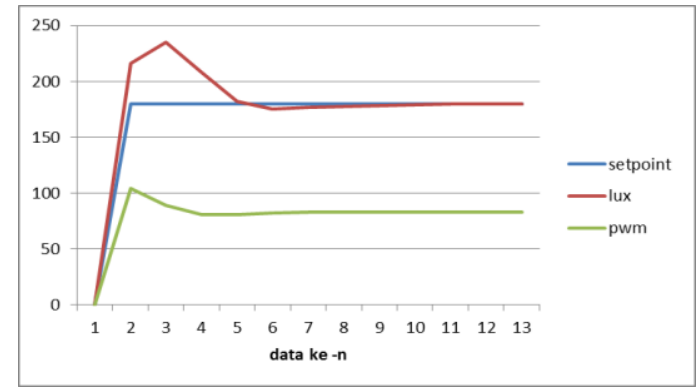

Gambar 11. Grafik pada mode makan

\section{Pengujian Pada Mode Kerja}

Pengujian pada mode ini bertujuan mendapatkan kecerahan pada saat bekerja di dalam sebuah ruangan. Set point yang diambil ialah 250. Berdasarkan hasil pengujian, didapat data pada Tabel V dan Gambar 12. Pada kondisi mode kerja, dapat kita lihat garis sensor membentuk kurva yang baik. Namun terlihat data yang abnormal pada pembacaan sensor di data ke3. Hal ini dapat terjadi karena komunikasi Arduino dan sensor yang mungkin memiliki noise. Jika dibandingkan dengan nilai PWM yang keluar, proses fuzzy tidak terganggu karena kesalahan pembacaan data ini.

TABEL V

DATA PADA MODE KERJA

\begin{tabular}{|c|c|c|c|}
\hline mode & setpoint (Ix) & Iux (Ix) & pwm \\
\hline \multirow{7}{*}{} & 0 & 0 & 0 \\
\cline { 2 - 4 } & 250 & 145 & 46 \\
\cline { 2 - 4 } & 250 & 84,17 & 76 \\
\cline { 2 - 4 } & 250 & 135,83 & 95 \\
\cline { 2 - 4 } & 250 & 185,83 & 110 \\
\cline { 2 - 4 } & 250 & 224,17 & 117 \\
\cline { 2 - 4 } & 250 & 247,5 & 117 \\
\cline { 2 - 4 } & 250 & 253,33 & 117 \\
\cline { 2 - 4 } & 250 & 252,5 & 117 \\
\cline { 2 - 4 } & 250 & 253,33 & 117 \\
\cline { 2 - 4 } & 250 & 254,17 & 116 \\
\cline { 2 - 4 } & 250 & 251,67 & 116 \\
\cline { 2 - 4 } & 250 & 250 & 116 \\
\hline
\end{tabular}

Data mulai terlihat stabil di data ke-13. Waktu yang dibutuhkan untuk lampu mencapai kecerahan stabil adalah (data ke $\mathrm{n}_{\text {titik stabil }}$ - data ke $\left.\mathrm{n}_{\text {titik awal }}\right) \times 300 \mathrm{~ms}=(13-1) \times$ $300 \mathrm{~ms}=3,6$ detik.

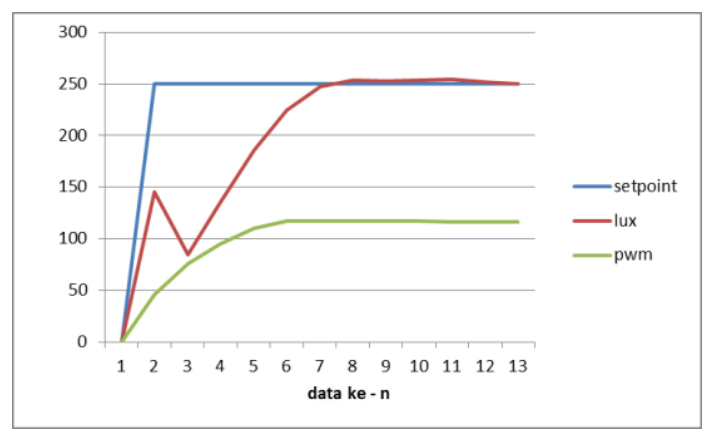

Gambar 12. Grafik pada mode kerja 
Perbandingan hasil pengujian dari ketiga mode dirangkum dalam Tabel VI. Dari pengujian yang dilakukan pada semua mode, dapat disimpulkan kecerahan mampu menuju set point yang kita tentukan dengan menggunakan fuzzy. Namun dalam praktiknya, sistem memiliki delay $300 \mathrm{~ms}$ setiap mengambil data karena sensor sendiri memerlukan waktu untuk mengambil data dan mentransmisikan nya ke Arduino. Data mampu menuju titik stabil dengan variasi waktu yang berbeda pada setiap mode.

TABEL VI

PERBANDINGAN DATA DARI 3 MODE

\begin{tabular}{|c|c|c|c|c|}
\hline \multirow{2}{*}{ Mode } & \multirow{2}{*}{ Sistem delay } & Set point & Waktu delay & \multirow{2}{*}{ Waktu stabil } \\
\hline Tidur & \multirow{3}{*}{$300 \mathrm{mS}$} & 40 & 1.5 second & data ke- 6 \\
\cline { 1 - 3 } Makan & 180 & 3 second & data ke- 11 \\
\cline { 1 - 3 } Kerja & & 250 & 3.6 second & data ke- 13 \\
\hline
\end{tabular}

\section{KESIMPULAN}

Aplikasi Blynk dapat mempermudah pengguna untuk menyesuaikan cahaya yang diinginkan. Arduino dan sensor cahaya dapat digunakan untuk mengolah data dan membaca nilai pada kecerahan lampu. Sistem yang di terapkan pada fuzzy mampu merepresentasikan nilai dari sebuah intensitas cahaya.

\section{REFERENSI}

[1] F. T. Nirwana and F. Arifin, "Alat Kendali Penerangan Ruangan dengan Logika Fuzzy Berbasis ATmega16," E-JPTE (Jurnal Elektron. Pendidik. Tek. Elektron., vol. 5, no. 1, pp. 25-31, Mar. 2016.

[2] N. Purwaningrum, "Aplikasi Fuzzy Logic untuk Pengendalian Penerangan Ruangan Berbasis Mikrokontroler ATMega8535," Universitas Negeri Semarang, 2007.

[3] L. A. Putra and A. R. Hakim, "Sistem Kendali Lampu Cerdas Pada Smarthome Berbasis Android mengunakan Metode Fuzzy Logic Control," CSRID (Computer Sci. Res. Its Dev. Journal), 2018.

[4] "Aplikasi Fuzzy Logic untuk Pengendali Motor DC Berbasis Mikrokontroler ATMega8535 dengan Sensor Photodioda," J. Tek. Elektro, 2015.

[5] ROHM, Digital 16bit Serial Output Type Ambient Light Sensor IC: BH1750FVI. ROHM Semiconductor, 2011. 